\title{
El uso de la discapacidad en la escritura espiritual medieval: particularidades religiosas
}

The use of disability in medieval spiritual writing: religious particularities

\author{
Petre Ene ${ }^{1}$ \\ Universidad de Toronto. Toronto, Canadá \\ petre.ene@mail.utoronto.ca \\ Código ORCID: 0000-0002-4376-6394
}

Citar como: Ene, P. (2019). El uso de la discapacidad en la escritura espiritual medieval: particularidades religiosas. Desde el Sur, 11(2), pp. 87-105.

\section{RESUMEN}

Los cuerpos discapacitados, aunque percibidos como un objeto de curiosidad, reflejan un sitio en el que convergen estereotipos culturales y religiosos, creando y destruyendo percepciones de malformaciones, reconfigurando roles sociales y planteando preguntas interesantes en el proceso sobre el cuerpo incapacitado y su lugar en el mundo medieval español. El objetivo de este trabajo es de abrir la conversación acerca de la relación simbiótica de los discapacitados y el «otro» en narraciones con un profundo contenido mitológico y espiritual cristiano, determinando una correlación entre el tratamiento que se da a una persona enferma y aquellos que confiesan un credo diferente a al credo de la audiencia. Con el propósito de determinar cómo funciona en la narrativa, la discapacidad, y en qué manera un problema se puede transformar en virtud, examino algunos rasgos que aparecen en las Cantigas de Santa María y en los Milagros de Nuestra Señora. La intención es establecer un vínculo entre la religión y la discapacidad.

\footnotetext{
1 Petre Ene es un estudiante de posgrado de la Universidad de Toronto, originario de Rumania. Realiza un doctorado investigando los libros teológicos de Francisco de Quevedo. Previamente, se graduó con distinción del programa de licenciatura en la Universidad de Alberta, Edmonton, donde se enfocó en la literatura española y la teología católica. Durante el programa de pregrado, exploró en parte la participación de la Iglesia en los asuntos políticos, sociales y económicos de los ambos lados del Atlántico, principalmente en el mundo de habla hispana. Con su maestría de la Universidad de Toronto en Literatura Medieval, descubrió su interés en la exploración de la conexión entre la literatura, la cultura y la teoría literaria de la primera modernidad. Actualmente, busca continuar sus estudios y su investigación sobre las producciones culturales formadas por la doctrina católica barroca.
} 
El trabajo toma en cuenta tanto la representación literaria, como también algunas ilustraciones del Códice Rico, donde se representan diversas discapacidades.

\section{PALABRAS CLAVE}

Cantigas de Santa María, discapacidad, iconografía, Milagros de Nuestra Señora, Berceo, Alfonso X el Sabio

\section{ABSTRACT}

Disabled bodies, perceived as objects of curiosity, reflect a scenario in which cultural and religious stereotypes converge, creating and destroying notions surrounding the idea of malformation, reconfiguring social roles, and raising interesting questions regarding the disabled body and its place in the Spanish medieval world. In this way, this work invites a conversation regarding the symbiotic relationship between the disabled and the "other" in stories deeply imbued with mythological content and Christian spirituality. The goal of this analysis is to identify a correlation between the treatment given to a sick person and those who confess a creed distinct from that associated with the reader's set of beliefs. In order to understand how the narrative uses disability and how a disadvantage can be transformed into a virtue, we will examine two medieval works: Cantigas de Santa María by Alfonso X and Los Milagros de Nuestra Seño$r a$ by Gonzalo de Berceo. The aim is to establish a link between religion and disability. We will consider both literary representation and certain illustrations from the Codice Rico, in which various forms of disability are depicted.

\section{KEYWORDS}

Cantigas de Santa María, disability, iconography, Los Milagros de Nuestra Señora, Berceo, Alfonso X the Wise.

El hombre medieval es consciente de su frágil vida y de que en su caminar en este mundo no se está solo, ya que diversos poderes sobrenaturales de carácter positivo lo ayudan a salvarse y le confieren la salud, mientras que los poderes de los demonios tratan de hacerlo caer en pecado mortal. Debido a la preocupación en las situaciones del mundo espiritual, el ser promedio de la Edad Media desarrolla una multitud de vínculos entre los fenómenos que no puede explicar racionalmente y la fe en lo sobrenatural. Lejos de ser una excepción, el espacio ibérico ve nacer una multitud de cuentos de carácter folclórico y religioso que apoyan y 
desenvuelven las historias de los santos, especialmente en aquellos sitios asociados con la peregrinación y la educación religiosa. Dos fuentes de mayor interés para el estudio de la espiritualidad ibérica medieval aparecen en forma escrita durante el siglo XIII. Me refiero a las Cantigas de Santa María (CSM), que se atribuyen al rey Alfonso X el Sabio, y los Milagros de Nuestra Señora (MNS), que es la obra capital de Gonzalo de Berceo.

Las dos colecciones contienen un gran número de milagros y castigos relacionados con diferentes formas de intervención divina, mediadas, principalmente, por la Virgen María. A pesar de que los dos textos tratan principalmente sobre el sujeto en la muerte inesperada, a nivel textual existe una variedad de hipóstasis en las cuales la discapacidad se presenta como elemento determinante de la historia. En principal nos referimos a los defectos físicos, pero en muchas otras situaciones la condición social o de género se interpreta también como una inferioridad, de tal manera que sugiere la existencia de la discapacidad, en relación con la norma. Mi pregunta de investigación está guiada precisamente en torno al papel que tiene la discapacidad en la narrativa. ¿Es que la discapacidad se usa para atraer la atención o es un elemento puramente decorativo basado en la realidad social? ¿O tal vez existe un mensaje que se puede vincular solamente con referencia a la incapacidad? En este ensayo me propongo explorar la manera en que la aparente tragedia de algunos personajes que se usan en el texto no solo como una prótesis literaria, sino que también se transforman en elementos de fortaleza en la virtud social y religiosa, e influyen con su presencia textual en el entendimiento del lector acerca de las maneras en que el sufrimiento del discapacitado sirve a la economía de la salvación. Con el propósito de determinar cómo funciona en la narrativa de la discapacidad, y de qué manera un problema se puede transformar en virtud, examino algunos rasgos sobresalientes de las dos obras, tratando de establecer un vínculo entre la religión y la discapacidad.

Seguiré exclusivamente aquellas partes que mencionan situaciones de discapacidad o requieren una discapacidad. En el presente trabajo, empezaré por analizar la caracterización directa de los personajes que presentan una forma de discapacidad, y continuaré por apropiarme la teoría de los estudios de discapacidad a la cultura española medieval en las CSM o de los MNS. Al mismo tiempo hablaré acerca de los conceptos teóricos que se implementarán a lo largo del ensayo. Con el propósito de examinar el uso de los personajes con discapacidad en la literatura, intentaré descifrar su manejo, explorando el posible impacto en el lector. También en el caso de las CSM trataré de relacionar, en algunos casos, el texto con la iconografía del Códice Rico, interpretando la imagen como representación visual fiel de la narrativa. 
Según David Mitchell y Sharon Snyder, en cada cultura se puede encontrar, de una manera o de otra, un trato de la discapacidad que presupone el descubrimiento de soluciones que mejor acomodan el medio ambiente para el uso del incapacitado (Mitchell y Snyder, 1988, p. 47). Esta búsqueda de la solución de acomodamiento genera una relación ambivalente entre la cultura de un lugar y la historia personal de los imposibilitados que viven en este espacio, y que se convierten en un objeto primario de la representación a nivel literal (Mitchell y Snyder, 1988, p. 47). A nivel de la cultura medieval, la relación del discapacitado con su mundo está determinada por la religión y las explicaciones de la fe acerca de la causa de la discapacidad. Por lo general, durante este periodo, se adolece del proceso de ajustar el medio ambiente para facilitar la vida del discapacitado; solo se observa la búsqueda de la solución curativa, principalmente por medio de una solución mágica.

Considerando que tanto la discapacidad física como las anomalías cognitivas prometen prestar un objeto tangible a la textualidad abstracta, al funcionar como una prótesis narrativa, la discapacidad genera su función simbólica a nivel textual y se trata como una experiencia social o política que se queda sin alguna manifestación (Mitchell y Snyder, 1988, p. 48). En el caso de la literatura con sustrato espiritual, la tradición y la escritura forman el cuadro necesario para argumentar el simbolismo de la discapacidad a nivel social y político, si consideramos la noción de política a la economía salvífica, tratando la relación individuo-Estado a través de la relación individuo-reino celestial.

El desarrollo de una gran variedad de eventos bíblico-folclóricos, que contiene la discapacidad presentada como castigo, tentación o elemento santificador, requiere, a base del razonamiento textual, una división. El Antiguo Testamento presenta la historia de Job, que relata la leyenda de una persona cuya fe está testeada por el demonio, y, por lo tanto, sufre de lepra, entre otras enfermedades. La base de la discapacidad en este caso sobresale de la idea central encontrada en el texto bíblico que se puede resumir a través de las palabras de Gustavo Gutiérrez, que reflexiona sobre la condición de inseguridad por parte de Job con respecto a la teología de la retribución ${ }^{2}$, pero mantiene una confianza total en su experiencia de vida (Gutiérrez, 1987, p. 27). Como vamos a ver más adelante, esta mentalidad se preserva en parte en la tradición de los milagros, especialmente en las situaciones en que la discapacidad se presenta como un ejemplo. 
San Pablo, nos comentan los Hechos de los Apóstoles, queda ciego al encontrarse con Jesucristo en medio de una experiencia mística (Hechos 9). En su caso, la ceguera es determinante para su proceso de santificación. La discapacidad, por lo tanto, se puede asociar a una llamada a la conversión. Por un lado, vemos la discapacidad como la forma de un castigo, y por el otro garantiza la revelación del poder divino. En todo caso, el modelo paulino se asocia con el concepto de conversión, y así se convertirá en la forma preferida de interpretación acerca de la deformidad.

Una categoría de razonamiento para la discapacidad encontrada en las fuentes bíblicas vincula esta realidad como marca generacional. En otras palabras, una enfermedad, un sufrimiento o hasta la muerte pueden reflejar los hechos de una familia y no del individuo. La presencia del imposibilitado tiene en sí mismo una narrativa. El castigo heredado a los hijos por culpa de los padres posee muchos ejemplos en los textos bíblicos. Mencionamos aquí, entre otros: los dolores del parto de las mujeres por culpa del pecado original (Génesis 3: 19), la muerte del primer nacido del faraón (Éxodo 11), la muerte del hijo de David engendrado por la esposa de Urías (2 Samuel 12) y la transmisión de los pecados de Israel a los hijos (Jeremías 16: 1-6). Todos estos ejemplos asumen un elemento de subtexto a nivel de castigo. Haciendo uso una vez más de las palabras de David Mitchell y Sharon Snyder, sugiero que tanto las CSM como los MNS, vistos como continuadores de la tradición bíblica, son representaciones que se integran a la teoría promovida por los dos teóricos antemencionados que afirman que si una historia «shares a literary objective of destabilizing sedimented cultural meanings that accrue around ideas of bodily "deviance"» (Mitchell y Snyder, 1988, p. 48). Entonces, el cuerpo discapacitado se puede percibir como un producto discursivo, tal como lo destacan las textos sagrados.

A la luz de las investigaciones de Brian Dutton acerca de la obra de Berceo, sabemos que el autor medieval, desde su primera estrofa, asegura que sus historias revelan con respeto a la verdad. Sin embargo, el mismo escritor admite la existencia de documentos con carácter falso que están realizados por parte de la jerarquía (Gerli, 1985, p. 13). La importancia de este detalle es significativa cuando discutimos el tono de la «autoridad irreprochable» que trata de transmitir Berceo (Gerli, 1985, p. 17) y el nuevo enfoque de la espiritualidad de este tiempo. Con el desarrollo monástico que siguió después de la reforma de Cluny, el culto de la Virgen y su importancia aumentaron (Gerli, 1985, pp. 19-20), y destacó su papel de mediadora en la salvación (Gerli, 1985, p. 21). Precisamente la necesidad de la mediación mariana nos determina a admitir que, para el fiel medieval, su vida espiritual se veía en necesidad de un intermediario para solucionar la incapacidad del ser, en acercarse hacia la divinidad. Interesante es que el 
culto de la Virgen surge como adyacente a la misión redentora de Cristo, y a la misión predicadora de la Iglesia. Sobresale el rol de María como invencible guardadora de autoridad, una autoridad que se interpone a la ley terrenal. Gerli afirma que los milagros recogen elementos de la tradición más amplia europea, ligando la fe y los conceptos folclóricos de las particularidades eclesiásticos locales (Gerli, 1985, p. 23). Sobre la base de esta conexión entre la fe, lo tradicional y la particularidad de mundo ibérico, tal como lo expresa Carmelo Gariano (Gerli, 1985, p. 33), nos atrevemos a añadir la peculiaridad de orden social que se mantienen presentes en la reverencia y la autoría sugerida por Berceo en sus historias. Consideramos los MNS como un fundamento para nuestro análisis de la discapacidad física en el mundo de la espiritualidad. Esta base fundamental es representada por el principio unificador que transforma «la alegoría que el mismo poeta expone en un sistema coherente de asociaciones e ideas» (Gerli, 1985 , p. 34). Por lo tanto, después de establecer el constructo general de los milagros, hablaremos sobre dos casos de discapacidad experimentados por cristianos y judíos.

Según Juan Manuel Cacho Blecua, «En cada uno de los milagros, Berceo recrea una intriga que apenas varía en lo esencial» (Cacho Blecua, s.f.), pero desarrolla una estructura interna diferente, manteniendo un modelo teórico compuesto por el marco narrativo y el milagro. Tal como explica Cacho Blecua, el marco narrativo corresponde al preámbulo y la síntesis en que un autor se dirige a sus «lectores-oyentes» (Cacho Blecua, s.f.). Al mismo tiempo, el milagro se manifiesta en relación con las circunstancias narrativas previas e introduce el «núcleo generativo, la acción que sirve de resorte al nudo de la acción» (Cacho Blecua, s.f.).

El primer ejemplo analizado, que además reflexiona sobre esta estructura, se encuentra en el tercer milagro, intitulado «El clérigo y la flor» (Berceo, 1985, p. 88). Este texto representa la historia de un clérigo que tenía muchos vicios, pero que también «era loco» (Berceo, 1985, p. 88). El vicio y la discapacidad, representada por la locura, son el preámbulo del milagro que requiere la intervención de la Virgen María después de ser asesinado y enterrado fuera de un cementerio. En el momento álgido se produce una intervención milagrosa, de la cual se sugiere la redención del pecador y su entrada en el Reino de Dios. La enseñanza didáctica de este episodio no se limita a la salvación del alma del clérigo, sino que implica la justificación de la discapacidad en la narrativa. Tal como podemos ver a nivel textual, «pero que era loco, avié un buen sentido, / amava la gloriosa de corazón cumplido» (Berceo, 1985, p. 88), la discapacidad arriba como un doble motivo. Por un lado, se puede interpretar como fuente del vicio, pero sobre todo representa el amor sin margen hacia la Virgen. Recordando un verso bíblico que 
dice: «Porque si estamos locos, es para Dios; y si estamos cuerdos, es para vosotros. Pues el amor de Cristo nos apremia» (2 Corintios 5: 13-14), la discapacidad se puede interpretar como una forma de bendición o don que determina la relación con la Virgen; en consecuencia, la salvación del alma. En este caso, la discapacidad sirve a la literatura de manera similar a una fuerza que se opone a la ordinariez cultural (Mitchell y Snyder, 1988, p. 48). Por lo tanto, la vulnerabilidad y la debilidad del ser incapacitado sirven al texto literario con una permutación que rechaza el deseo del pensamiento racional hacia el orden y el conformismo, y funciona como una metáfora del cuerpo rebelde que desafía la normalidad impuesta (Mitchell y Snyder, 1988, p. 48). Si se siguiera esta normalidad, no alcanzaría la salvación divina. De esta manera, en esta situación podemos deducir que la discapacidad funciona como una prótesis narrativa con carácter espiritual.

El segundo texto de los MNS que presenta a un discapacitado cristiano es el milagro 12, «El prior de San Salvador y el sacristán Uberto» (Berceo, 1985 , p. 120). Es la historia de un buen y piadoso prior exiliado, que sufrió mucho, y cuya alma no encuentra descanso por no haber recibido los protocolos y procedimientos para una buena muerte. La Virgen puede comunicarse de manera mística con un sacristán llamado Uberto. En esta instancia la discapacidad ocupa un papel menos importante, al ser vinculada como parte del sufrimiento a través de las palabras del prior: «Sufrí mucho lazerio». Este término antiguo, derivado del latín lacerāre, se puede traducir contextualmente como «sufrimiento físico» y puede considerarse una discapacidad. Una estrofa más adelante, el personaje confiesa que la Virgen lo agarró de la mano y lo llevó a un lugar sin peligro (Berceo, 1985, p. 122), lo que denota su incapacidad de encontrar refugio. El peso de la materialidad «corporal» funciona como texto y una expresión cultural a la vez. El prior se manifiesta como un fantasma. Su cuerpo se convierte en un elemento transcendental, por culpa de la discapacidad provocada que lo lleva de la mano hacia la muerte. Aquí hablamos de un «otro» que representa un lenguaje metafórico, escandaloso o chocante, que va más allá de la capacidad del texto por controlarlo (Mitchell y Snyder, 1988, p. 49).

En un mundo en que la muerte, la superstición y la fe influyen muchos aspectos cotidianos, existe una cultura popular de interpretación acerca del destino de un alma después de la muerte física. Durante la Edad Media la población se preocupaba mucho por el concepto de vida eterna. Las personas intentaban acercarse a la conversión espiritual, especialmente una vez identificada la inminencia de la muerte. La inhabilidad de seguir con los requisitos del ars moriendi determina que el destino del ser medieval sea indirectamente definido por la mentalidad social y religiosa de la época. El alma de la persona es condenada al infierno, por no poder 
confesarse y por vivir una vida pecaminosa desligada de la doctrina cristiana. La muerte inesperada, como consecuencia del crimen, catalogado como «uno de los delitos más habituales de la sociedad medieval» (Iglesias, 2015, p. 61), se puede interpretar como advertencia social hacia el carácter vicioso de una persona. A la luz de la interpretación bíblica, todos los que vivían en tinieblas y pecado eran supuestamente sorprendidos por una muerte inesperada, tal como lo afirma el texto del Apocalipsis de San Juan: «Acuérdate, pues, de lo que has recibido y oído; y guárdalo, y arrepiéntete. Pues si no velas, vendré sobre ti como ladrón, y no sabrás a qué hora vendré sobre ti» (Apocalipsis 3:3).

La representación de la separación entre texto y cuerpo se concibe similarmente como a un elemento que proviene de la enseñanza de Descartes. Tomando en consideración que los conceptos acerca de la discapacidad cambian tras el paso del tiempo, David Mitchell y Sharon Snyder argumentan a favor de que la condición del incapacitado es en realidad un privilegio en la dicotomía cuerpo-alma, y sirve a manera de huella simbólica que se deja interpretada por el discurso del cuerpo (Mitchell y Snyder, 1988, p. 49). Es decir, el «lazerio» funcionando a nivel textual como una puerta de comunicación entre el cuerpo físico y el mundo espiritual, garantizando al protagonista la comunicación con Uberto para beneficiar el ars moriendi.

Bajo el título «El judezno» (Berceo, 1985, p. 132) se destaca nuestro tercer milagro, la historia de un niño de origen judío que comulga. Al enterarse su padre, lo introduce en un horno encendido. Por intervención de Santa María, el niño no recibe ningún daño y es salvado. La narración no muestra discapacidad o muerte después de ser quemado vivo en un horno. En esta situación la protección de la Virgen se da como resultado del deseo de conversión por parte del «cordero sin lana» (Berceo, 1985, p. 133). Si el cuerpo funcional no tiene su esencia definitoria, y pasa como normalidad, el cuerpo discapacitado presenta una particularidad (Mitchell y Snyder, 1988, p. 49) (casi exótica) que se puede narrar como elemento fuera de la regularidad. En varias obras la presencia del elemento con discapacidad aparece como elemento fundamental que recuerda al lector acerca de lo normal, y refuerza la norma tras la yuxtaposición a nivel narrativo normal-anormal o utilizando la expresión de David Mitchell y Sharon Snyder, una narrative prosthesis (Mitchell y Snyder, 1988, p. 49). En esta instancia, la falta de discapacidad argumentada en medio de la intervención milagrosa también sirve como prótesis y reemplaza la ocurrencia esperada por un evento sin incapacidad o daños.

Al comparar las tres ocasiones vinculadas con la discapacidad en el texto de Berceo se evidencia fácilmente una diferencia en el uso de la incapacidad a nivel literario. En los dos casos que tratan con el sufrimiento 
de un cristiano, la discapacidad es un elemento determinante en la reafirmación de la fe. En el primer caso, la locura sostiene la devoción hacia la Virgen y garantiza al difunto el acceso a la vida eterna. En el segundo caso, el sufrimiento físico, a pesar de conducir hacia la muerte física, le permite comunicarse con las autoridades eclesiales para seguir las costumbres de la fe en relación con la muerte inesperada. Por lo contrario, la protección del no bautizado, que consume la eucaristía a pesar de no ser cristiano y se percibe como un sacrilegio a causa del pecado original, revela a nivel textual el regalo hacia la vida. No solo el judío no muere o queda herido en el horno, sino que el don de la vida está doblado por la imagen espiritual de la vida eterna. El cuerpo inmaculado, semejante a un cordero, no se consume en el fuego purificador, y por ello no hay signos de discapacidad. Esto se evidencia en la correspondencia al personaje antagónico que se queda en cenizas. La discapacidad atribuida a los judíos en esta situación sería probablemente un castigo por un pecado arrepentido.

A diferencia de la narrativa de Berceo, que tiene como propósito la instrucción y la fomentación de la fe en el camino de la peregrinación, las CSM escritas por Alfonso X cumplen una función educativa. Esta obra, tal como afirma Montoya en su introducción a las Cantigas, se enfoca en el «convencimiento de la mentalidad religiosa medieval en la que cualquier acción divina operada entre los hombres redundaba en alabanza de Dios y sus intermedios, los santos» (Montoya, 1988, p. 20). El rey Alfonso X pertenece a una generación de trovadores que tiene dificultad en separar lo sacro de lo profano (Montoya, 1988, p. 16). Por lo tanto, el principal propósito de su escritura es exaltar a la Virgen María de igual manera en que se realiza la exaltación de la amada. Durante el siglo XII el amor apático se compara al amor impaciente. El paralelismo entre lo secular y lo sagrado recibe mucha popularidad durante esta época, y determina que las descripciones psicosomáticas anteriormente identificadas por la medicina sean asociadas con el amor místico (Wack, 1990, p. 23). Los discursos de los místicos continuarán introduciendo la terminología de la medicina en sus reflexiones sobre el deseo por el amor divino. Consecuentemente, esta misma tendencia seguirá con el desarrollo de la imagen de Cristo como amado (Wack, 1990, p. 24), y en el caso de las CSM, la Virgen como doncella, que requiere la fieldad del trovador. Según Wack, el sacrificio de Cristo y la veneración de la cruz implementan elementos que provienen del erotismo (Wack, 1990, p. 25), conceptos que se pueden apreciar en algunos textos de Alfonso $X$, que se declara en el prólogo trovador de María (O'Callaghan, 1998, p. 15).

Los personajes de esta obra son representantes de diversos grupos sociales, religiosos e intelectuales, que «comparten en común sus acciones 
transgresoras y, mediante su fe en la Virgen, expían sus pecados, se arrepienten y salvan su alma de su propia maldad» (Domínguez-Navarro, 2010, p. 302). A medida que el pecador no acepta a la Virgen y su culto, recibe una condena, que suele ultimar con la muerte. John Keller explica que, para entender la didáctica de los milagros presentados en el intermedio de las historias de los personajes, en la cantiga se necesita considerar tres expresiones, la poética, la melódica y la visual (Keller, 1981, p. 138). A pesar de que las cantigas fueron escritas como representaciones públicas cantadas en la corte y en las iglesias, en el presente trabajo exploraremos solo dos de estos aspectos, el poético y, parcialmente, las representaciones visuales, a través de un número limitado de milagros que integran el concepto de discapacidad. En las siguientes secciones exploraremos el impacto de la incapacidad de un judío, de un musulmán, y cómo se aplica este concepto para la población cristiana. Las ilustraciones que serán analizadas en paralelo con la historia tendrán como proveniencia el Códice Rico.

Un primer texto que habla sobre una forma de discapacidad es la cantiga 4. La historia es muy similar a lo que encontramos en la escritura de Berceo, el milagro con el título «El judezno» (Berceo, 1985, p. 132). Para no destacar los mismos vínculos acerca de la protección que mantiene a salvo al niño en el horno y no le genera ninguna discapacidad, nos enfocaremos en la inhabilidad representada por la locura del padre. Al final del texto el autor menciona: «Por milagro tal, luego la judía creía y el niño, sin más, recibía el bautismo, y el padre hiciera el mal, por su locura, le dieron entonces una muerte como él quiso dar a su hijo Abel» (Alfonso X, 1979, p. 16). De este fragmento sobresale que detrás de la acción del padre no estaba el racionamiento normal, sino una enfermedad. A pesar de que Alfonso $X$ presenta la realidad del judío, su acción está de todas maneras condenada. La existencia de una discapacidad no elimina el castigo; todo lo contrario, su locura se utiliza como argumento para condenarlo hacia la muerte.

En este episodio se aprecia cómo la discapacidad de un personaje no sirve como excusa ante el castigo que recibirá. Si la falta de la discapacidad que hemos discutido en la sección de Berceo fomentaba la conversión, a este nivel la locura se trasforma en la motivación para la muerte. La marginalización social, o mejor dicho la eliminación de la persona, revela el concepto de acción y castigo que se practicaba en la sociedad medieval. Indiferentemente de las circunstancias de un delito que surge en contra de una persona que se asocia con el culto cristiano, requiere un castigo categórico como la muerte.

En la cantiga 21, la Virgen logra una resurrección infantil de un bebé nacido por una mujer considerada estéril (Alfonso X, 1979, pp. 48-49). La 
esterilidad como discapacidad tiene unan gran tradición bíblica. No obstante, en el texto de las CSM una mujer pide en lágrimas la intervención de la Madre de Dios, Theotokos (Scarborough, 1993, p. 39), para que ella misma se convierta en la madre de un varón, demostrando de esta manera la responsabilidad de la mujer casada de engendrar hijos, especialmente de género masculino. Pero la especificación del género sugiere que ser mujer en la época es una forma de discapacidad. La idea central de esta afirmación se acerca de la tesis encontrada en el capítulo «Theorizing disability», de Rosemarie Garland Thomson, que sugiere un paralelismo entre la manera de percibir a la mujer y la percepción del discapacitado, tal como se les representa en la producción cultural, con el propósito de cambiar el discurso acerca de las dos entidades marginalizadas. Siguiendo la trayectoria establecida por Aristóteles, a los dos se les representan en contraste con el hombre, definido como plenitud de la creación y de la existencia humana, un símbolo de la plenitud y la creación sin mancha. Por lo tanto, a la mujer y al discapacitado se le exteriorizan en la producción cultural que posteriormente se desarrolla en la percepción social similarmente al hombre mutilado (Garland Thomson, 1997, p. 20).

Esta representación se nota en el personaje cuya función reproductiva está al servicio del hombre para engendrar más hombres y recibe un doble nivel de discapacidad. Por un lado, «el hombre mutilado», que es la mujer que vive en sí misma la discapacidad y, por el otro, la función principal de este ser como contribuyente a la perpetuación de la raza se ve afectada a nivel de la reproducción. La importancia de esta doble inhabilidad se contradice con dos rasgos fundamentales de la mariología. Primero que todo, hablamos aquí del papel de María en relación con el desarrollo de Jesucristo antes de su ministerio público, un desarrollo fundamental para confirmar la responsabilidad de la mujer en la sociedad. En segundo lugar, tenemos que relacionar la esterilidad como discapacidad frente al concepto del vientre fecundo de Santa María, que se destaca como contribuyente a la encarnación obra del Espíritu Santo. En conclusión, a nivel narrativo la discapacidad de la mujer estéril cristiana funciona como elemento marcador de las cualidades pertenecientes a la mujer perfecta, la nueva Eva del cristianismo. El problema se presenta como razón para obtener los dones más importantes de la Virgen: la maternidad y la corresponsabilidad de la vida vinculadas a la resurrección de Cristo y a la resurrección milagrosa del hijo de la mujer estéril.

A este último aspecto se le puede añadir un paralelismo más. Tanto la Virgen como la mujer de la cantiga no conciben como fruto de las relaciones sexuales; por lo tanto, el elemento milagroso hacia la discapacidad reproductiva indubitablemente se transforma en un vaso para la gracia de 
Dios. Este concepto, que nace de la condenación medieval hacia la sexualidad y tiene como fundamento las palabras de Pablo de 1 Corintios 7, revela el gran honor de la fecundidad espiritual. Garland Thomson pretende poner de manifiesto la importancia y el beneficio de considerar un vínculo entre los estudios de género, más precisamente las teorías feministas y el análisis acerca de la discapacidad, con el propósito de contribuir en los estudios acerca de la discapacidad. Aún más, ella considera mutualmente beneficioso traer la teoría feminista a los estudios de la discapacidad, pues visualiza una infusión de la teoría de género en el vínculo entre el sentido atribuido al cuerpo por las representaciones culturales y las consecuencias de sus significados en el plan universal (Garland Thomson, 1997, pp. 20-21). Por lo tanto, al comparar la percepción y la representación de la desigualdad representadas a nivel sociocultural en las producciones literarias, con respecto a la mujer, que se encuentra en la misma posición de desventaja experimentada por la persona con discapacidad, la realidad discriminatoria de los dos sugiere la necesidad de una colaboración entre ambas partes en el mundo medieval, para demostrar la intervención del mundo espiritual. El crecimiento espiritual garantizado por el evento con sus dos formas de inhabilidad señala, sin duda, que la discapacidad de la mujer cristiana es en realidad un don que la acerca a la dignidad mariana, un importante estado para una madre.

Un episodio con mayor dramatismo y una forma común de discapacidad se encuentra en la cantiga 37, donde se relata la historia de un hombre cristiano que pierde su pie cortándola (Alfonso X, 1979, p. 74). La cojera es doblada por la presencia de la lepra. A pesar de que el texto no detalla la causa de la enfermedad - destaca solo el gran sufrimiento que determina al enfermo a recorrer un gesto dramático-, se nos menciona la norma detrás de la desgracia del personaje. La narración subraya lo siguiente sobre Santa María: «hace milagros hermosos y maravillosos, para que creamos en Dios y lo temamos más» (Alfonso X, 1979, p. 74). Desde un buen principio la discapacidad funciona como prótesis para la realización de una espiritualidad más ferviente.

En el Códice Rico, uno de los manuscritos que se preservaron de las CSM, a través de las imágenes en miniatura, se nos presenta un mensaje literario adyacente que realiza una serie de conexiones con los lectores, lo que aumenta la comunicabilidad del texto. Antes de pasar a su estudio detallado, apuntaremos que el arte de las CSM es «la misma sencillez ingenua que se observa en la esfera de lo narrativo, [y] en la esfera de su expresión plástica» (Guerrero, 1949, p. 25), apuntando hacia su natura civil y no religiosa. En otras palabras, a nivel de miniaturas se pueden apreciar un conjunto de rasgos que pertenecen a la peculiaridad de la sociedad 
ibérica de siglo XII (Guerrero, 1949, p. 25). En la figura 1, que proviene del códice mencionado, se desenlaza la narrativa de la cantiga a través de una serie de nueve ilustraciones que acompañan el texto de Alfonso X.

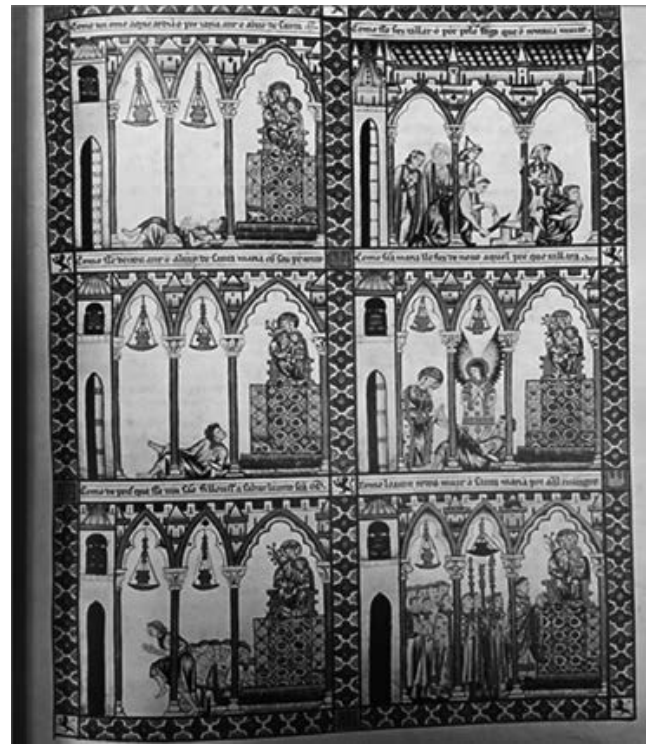

Figura 1

Con la excepción de la segunda imagen, en la cual se le corta el pie al hombre, toda la acción se destaca al interior de la iglesia. Es interesante observar que la Virgen está representada como la Madre de Dios, y el traje del hombre es azul claro, un color mariano que parece sugerir la devoción hacia Santa María. A juzgar por el lugar de la acción, nos encontramos con una forma de consagración hacia el poder materno de la Virgen. El protagonista, en las primeras imágenes, se encuentra en la parte inferior del dibujo, en oposición a la estatua de la Virgen o al grupo de personas que lo dejaron cojo. Este balance en la composición permite al público darse cuenta de la oposición entre la enfermedad y luego discapacidad, y lo normal. Al mismo tiempo, considerando que la razón detrás de la enfermedad es la lepra, que en muchos casos se asocia con los pecados carnales, la oposición entre el enfermo y la Virgen, guardadora de la pureza, se evidencia aún más. El milagro se produce después de que la Madre de Dios lo toca. La didáctica del cuadro sugiere la acción que debe tomar cualquiera que se siente llamado a la santidad, es decir, cuidar de los enfermos. La discapacidad se destaca como llamada a la unidad de la gente, algo que se hace evidente en tres de estas imágenes, donde encontramos un grupo colectivo. Tobin Siebers dice que la estética rastrea las sensaciones que 
algunos cuerpos sienten en presencia de otros cuerpos (Siebers, 2010, p. 25). Según él, la idea de llevar el procedimiento hacia más allá involucra una relación que tiene su implicación en el arte y lo que ocurre cuando hay discapacidad en el arte. La manera en que el público percibe la discapacidad se vincula con la estética y el arte visual, que implican un espacio fijo y que pueden ser percibidos como antítesis de la narración, a causa de la manera estática de una temporalidad fija. En nuestro caso, esta sería representada por el Medioevo y determinada por los conceptos analíticos del público (Siebers, 2010, pp. 25-26). Juntando al discapacitado con los normales, y presentándolo como parte de la iglesia, la narrativa realiza un espacio en el cual el sufrido puede vivir. Su representación como miembro de la colectividad aparece como una confirmación de su dignidad. En esta situación la representación del discapacitado devoto tiene el rol educativo de romper con las barreras sociales y de acercar al enfermo hacia el culto de la Virgen.

Hasta ahora hablamos principalmente acerca de milagros que curan o evitan los resultados de la enfermedad o de la discapacidad. Sin embargo, en las CSM existen algunos casos en que la discapacidad es resultado de una transgresión en contra de la Virgen. En la cántiga 108, por ejemplo, se nos relata la historia de un judío que se negaba a creer el papel de María en la historia de la salvación, y que entabla una discusión con el brujo Merlín, figura legendaria de la literatura medieval paneuropea. Como resultado al desahogo antidoctrinal por parte del judío, Merlín lo maldice en el nombre del Dios cristiano, y desea que su hijo nazca con una malformación facial (Alfonso X, 1979, p. 187). Al final de la narrativa se afirma que el rostro del niño era «de delante atrás» (Alfonso X, 1979, p. 187), lo que condujo al judío a intentar matar a su hijo. Continúa la historia testimoniando que «Merlín lo hizo guardar, y lo entendió muy bien, para sacar a los judíos del error, pues creció y, con ello, los convertía» (Alfonso X, 1979, p. 187).

Conforme con la evidencia textual, se puede afirmar que en este caso la discapacidad del niño judío es objeto testimonial en contra de una creencia religiosa. Aplicando la cultura medieval referida a la enseñanza sobre el arte moderno de Anita Silver realizada según la lectura de Siebers, señalamos que se puede argumentar que si el arte se preocupa tanto por la deformidad corporal, como la imitación del natural (el resto) y de las referencias figurativas (volverse atrás), entonces debería servir como instrumento educativo implementado en la educación social de los ciudadanos y los valores doctrinales cristianos, como la maternidad de María. Esta integración conceptual de la deformidad corporal favorece ulteriormente a los individuos, que de tal manera podrán apreciar la belleza del cuerpo discapacitado en lugar de rechazarlo (Siebers, 2010, p. 43), como 
lo hicieron tradicionalmente debido a la falta de motivación espiritual. Desde el medio de esta posición, como lectores nos podemos dar cuenta de dos planteamientos. Primero, el cuerpo discapacitado del judío está discriminado socialmente en la sociedad cristiana, ya que no es el pecado del individuo, sino de la familia. En segundo lugar, la representación literaria favorece o desfavorece el constructo social tradicional de lo bonito, lo aceptable y lo normal, y determina a través del normativismo estético de la marginalización de la figura discapacitada. Me atrevo a vincular esto con el concepto foucaultiano del biopoder.

De la enseñanza de Michel de Foucault de la clase de 17 de marzo de 1976 , sabemos que las violaciones se presentan socialmente como un símbolo de la dominación racial. Una representación de esta realidad se encuentra a nivel narrativo en la cantiga 187, donde la mujer judía, y a través de ella su hijo, son explotados por Merlín para dominar al hombre judío de la historia. Descifrando los sucesos de la obra a la luz del contexto de la teoría de Michel de Foucault, las mujeres son violadas disciplinariamente (Foucault, 2001, pp. 227-228). De esta manera, se les niega los derechos no solo a la palabra — la mujer no menciona nada en la narrativa-, sino también a la posibilidad de administrar sus funciones reproductivas. Hasta en un contexto puramente machista, en el cual la mujer es posesión de su esposo, y por lo tanto su inhabilidad de protegerla ante la maldición de Merlín, se traduce de manera metafórica en la castración del macho. La inferioridad del otro se construye a través de un ejemplo de discapacidad heredada por el nuevo nacido.

El biopoder que regulariza al otro, sin duda. Un elemento del barbarismo presentado en esta historia no solo tiene una función de aumentar el carácter trágico, además, la transgresión de orden reproductivo encaja tres valencias relacionadas con la discapacidad. Ante todo, podemos hablar de la normalización del otro, percibido como un salvaje (o discapacitado), que se puede dominar solamente con el uso de la fuerza destructiva de la maldición. De igual modo, tenemos la implementación de las doctrinas cristianas y la manifestación del poder de la Virgen como argumentos para la agresión (la discapacidad del niño se usa para la conversión) que se interpretan a modo de un acto justificado por el deseo de mejorar la humanidad entera. Merlín usa al discapacitado como un arma civilizatoria y de blanqueamiento racial ante el peligro de reproducción del otro, considerado inferior.

Por último, tras la existencia de la agresión con implicación hereditaria, y considerando que la cantiga se trata de una mujer casada, víctima de una maldición y no del resultado de sus acciones, se tiene, como lo mencionamos anteriormente, una valencia de castración hacia el marido incapaz 
de ofrecer protección. La transgresión y el uso de la mujer como objeto de deseo que satisface las necesidades de dominación del agresor castiga de manera simbólica al judío incapaz de perpetuar exitosamente su legado.

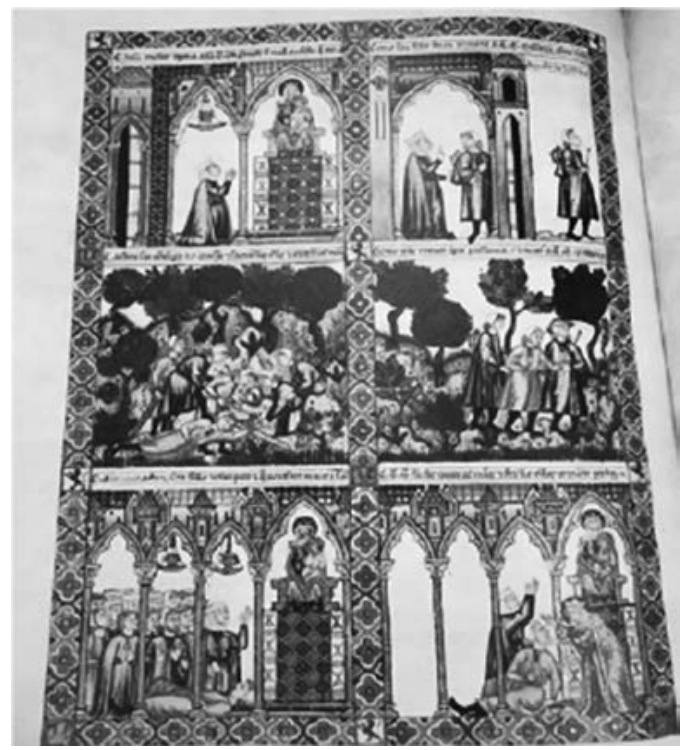

Figura 2

Después de discutir sobre la discapacidad del concepto de biopoder ejercitado en contra de un representante de la comunidad judía, para no pensar que este tipo de relación existía solamente con la gente de otras religiones, es importante mencionar otra historia donde la capacidad destructiva del enemigo discapacita a una persona con fines de dominación. En la cántiga 146, la Virgen realiza el milagro de la recuperación de miembros perdidos. La historia presenta a un joven que está de romería, y al encontrarse con dos de sus enemigos, estos lo dominan, le cortan las manos y le sacan los ojos (Alfonso X, 1979, pp. 245-246). Tal como se aprecia en la representación visual de la figura 2 , el autor presenta una historia circular que empieza con la madre que reza hacia la Virgen y termina con la mujer dándole gracias a Santa María. Esta manera de presentar la historia sugiere que lo que realmente importa es la fidelidad de la fe por parte de los personajes.

En la figura 3 se dibuja el trágico encuentro del joven y sus dos enemigos. La narrativa da testimonio acerca de lo que le ocurre al protagonista: «uno de aquellos malos, incrédulos, le sacó los ojos y después le cortó las manos con una falce» (Alfonso X, 1979, p. 246). El uso de la palabra incrédulos como descripción de los agresores sugiere un alejamiento de la fe 


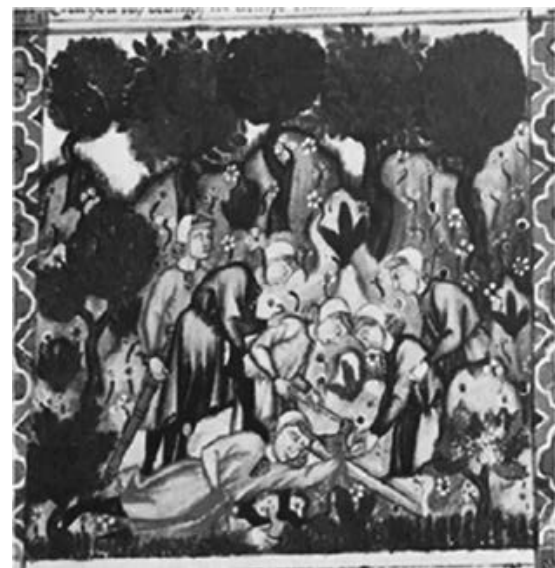

Figura 3

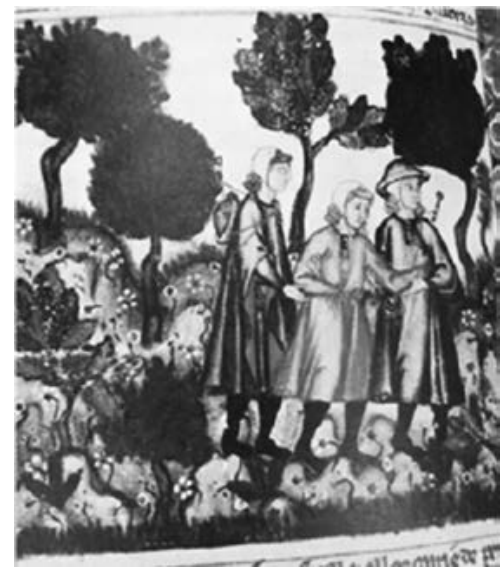

Figura 4

por parte de ellos. Asimismo, aumenta el antagonismo entre el joven y los enemigos. Además, el acto de sacar los ojos a una persona se presenta a nivel metafórico como un intento de eliminar su devoción hacia la Virgen, la entidad por la cual está en peregrinación.

La historia en causa tiene su ambivalencia. Por un lado, tenemos un valor simbólico representado por el poder eficaz que sobresale de su inhabilidad de ver el obstáculo. En otras palabras, en el caso de este personaje, la incapacidad sinónima con la ceguera, que aparentemente es un obstáculo que determina en la narrativa su devoción y su actitud única hacia Santa María. Contrario a todas las expectativas, el joven continúa su peregrinación y está convencido de su curación por mediación de la Virgen. Otro peregrino se convierte en sus ojos. En la figura 4 el artista pone en perspectiva el obstáculo del discapacitado y es alcanzado a través de la colaboración entre distintos miembros de la Iglesia. Esta imagen recuerda los distintos miembros del Cuerpo de Cristo que están animados por el mismo Espirito Santo (1 Corintios 12:12-14).

Asimismo, podemos argumentar que, a través del texto y de la representación visual, la cuestión de la discapacidad se percibe como una descripción indirecta del personaje. Me refiero a la discapacidad como elemento que ofrece una información acerca de la identidad original del personaje, a pesar de retener un carácter de pragmatismo y misterio (Mitchell y Snyder, 1988, p. 50). En el caso del joven, la narrativa retiene el pragmatismo y el secreto de su pasado, porque no sabemos cómo logró tener enemigos. Sin embargo, la ceguera no es tampoco una incapacidad causada por el pasado. El desarrollo de la discapacidad en el tiempo de la narrativa fortalece la hipótesis de que la invalidez ennoblece al personaje y lo determina a demostrar su devoción en la peregrinación por la Virgen. 
Partiendo de la teoría adaptada de Lacan por Richard Powers, que sugiere que el cuerpo funciona como un lenguaje, la presencia de la discapacidad ofrece una explicación en relación con todo o con nada, de los seres encarnados (Mitchell y Snyder, 1988, p. 50). El joven se ve en posición de realizar un camino a ciegas, y posterga a nivel metafórico la noción de creencia sin ver. Es un rasgo de antagonismo con el apóstol Tomás, que refuta la creencia en la encarnación hasta el momento que toca las heridas de Cristo crucificado, según el evangelio de San Juan, capítulo 20.

El autor de la cantiga usa lo que la historia y la cultura describen como elemento pervertido, y lo transforma en un cuerpo con su marca textual (Mitchell y Snyder, 1988, p. 54). Parafraseando a Barbara Maria Stafford, tenemos una posibilidad singular de ser saludables, pero una multitud de maneras únicas por las cuales nos podemos enfermar (Mitchell y Snyder, 1988 , p. 54). Sugiero una vez más que la legitimidad del ciego en la obra absorbe su savia precisamente de la amistad y la cercanía hacia Santa María, que conduce el hilo narrativo y lo transporta a su destino.

El valor didáctico que podría ser identificado por el público en muchas obras de Berceo o de Alfonso X muestran su carácter comprensible, a través del cual se convence al fiel de los males del pecar y del premio que se recibe al arrepentirse. Como se aprecia de este análisis, el concepto de discapacidad funciona en una multitud de variedades para satisfacer la necesidad de ejemplificar al público partes de la doctrina cristiana y el culto asociado con la Virgen María. También pudimos identificar una manera diferente en el uso de la discapacidad asociada con los judíos, donde la discapacidad puede funcionar como elemento determinante en la conversión hacia el cristianismo. Al final de nuestro análisis concluimos que el uso de los rasgos de incapacidad son una prótesis narrativa a través de la cual las anomalías cognitivas y la falta de miembros prestan un objeto tangible a la textualidad abstracta. Son elementos estéticos antagónicos que vienen en el auxilio de las leyendas moralizadora de la época.

\section{Contribuciones}

Petre Ene ha participado en la concepción del artículo, en la recolección de datos, en la redacción y aprobación de la versión final.

\section{Fuentes de financiamiento de su artículo}

Fondos propios.

\section{Conflictos de intereses del artículo}

Ninguno. 


\section{REFERENCIAS BIBLIOGRÁFICAS}

Alfonso X (1979). El Códice Rico de las cantigas de Alfonso X el Sabio. Madrid: Edilán.

Berceo, G. (1985). Milagros de Nuestra Señora. Madrid: Cátedra.

Blecua, J. (s. f.). Género y composición de los Milagros de Nuestra Señora de Gonzalo de Berceo. Recuperado de www.vallenajerilla.com/berceo/cachoblecua/generoycomposicionmilagrosberceo.htm.

Domínguez-Navarro, D. (2010). Fervor religioso y antisemitismo en los Milagros de Nuestra Señora de Gonzalo de Berceo. Lemir, 14, pp. 301-312. Recuperado de parnaseo.uv.es/lemir/Revista/Revista14/18_Dominguez_ David.pdf

Foucault, M. (2001). Defender la sociedad. Buenos Aires: Fondo de Cultura Económica.

GarlandThomson, R. (1997). Extraordinary Bodies. Nueva York: Columbia UP. Gerli, M. (1985). Introducción. Milagros de Nuestra Señora (pp. 11-66). Madrid: Cátedra.

Guerrero, L. (1949). Las Cántigas: estudio arqueológico de sus miniaturas. Madrid: Consejo Superior de Investigaciones Científicas.

Gutiérrez, G. (1987). On Job: God-talk and the Suffering of the Innocent. Maryknoll: Orbis Books.

Iglesias, Y. (2015). Implicaciones legales de las seis muertes en La Celestina: Un acercamiento histórico- literario. Romance Quarterly, 62(2), pp. 59-70.

Mitchell, D. y Snyder, S. (1988). Narrative Prosthesis. Ann Arbor: Universidad of Michigan.

Montoya, J. (1988). Introducción. Cantigas (pp. 11-89). Madrid: Cátedra.

O'Callaghan, J. (1998). Alfonso X and the Cantigas de Santa Maria: A Poetic Biography. Leiden Netherlands: Brill.

Scarborough, C. (1993). Women in Thirteenth-Century Spain As Portrayed in Alfonso X's Cantigas de Santa Maria. Lewiston: Mellen Press.

Siebers, T. (2010). Disability Aesthetics. Ann Arbor: University of Michigan Press.

Wack, M. (1990). Lovesickness in the Middle Ages: The Viaticum and Its Commentaries. Filadelfia: University of Pennsylvania Press.

The Lockman Foundation (s. f.). La Biblia de las Américas. Recuperado de bibliaparalela.com/lbla/2_corinthians/5.htm 